\title{
Effect of Methylprednisolone on CSF IgG Parameters, Myelin Basic Protein and Anti-Myelin Basic Protein in Multiple Sclerosis Exacerbations
}

\author{
Kenneth G. Warren, Ingrid Catz, Verona M. Jeffrey and Dorothy J. Carroll
}

\begin{abstract}
Clinical exacerbations of multiple sclerosis (MS) are characterized by elevated levels of cerebrospinal fluid (CSF) myelin basic protein (MBP). The purposes of this study were to determine whether anti-MBP antibodies are present in increased titer in CSF of MS patients with exacerbations, and whether they can be suppressed by the administration of immunosuppressive dosages of methylprednisolone (MP). A solid phase radio-immunoassay (RIA) was used to detect free and total anti-MBP antibodies before and after acid hydrolysis of CSF. In MS exacerbations, the majority of elevated anti-MBP is in the free form. With the exception of subacute sclerosing panencephalitis (SSPE) and some cases of post infectious encephalomyelitis, anti-MBP antibodies are not present in either MS patients in remission or in non-MS controls. Anti-MBP levels remained elevated over a 10 day period when patients are managed by bed rest only or when treated with intravenous (IV) ACTH. IV administration of MP in "high" (160 $\mathrm{mg} /$ day) or "mega" ( $2 \mathrm{~g} /$ day) dosages produces a highly significant reduction of both MBP $(\mathrm{p}<0.01)$ and anti-MBP $(p<0.001)$ levels. Total intrathecal IgG synthesis is also significantly suppressed by IV-MP but not by ACTH.
\end{abstract}

RÉSUMÉ: Le traitement par la méthylprednisolone d'une élévation des anticorps anti-protéine basale de la myéline dans la sclérose en plaques Les exacerbations cliniques dans la sclérose en plaques (SEP) sont caractérisées par une augmentation du taux de la protéine basale de la myéline (MBP) dans le liquide céphalo-rachidien (LCR). Le but de la présente étude était premièrement de déterminer si les anticorps anti-MBP étaient en taux plus élevés dans le LCR au cours des poussées de la maladie et deuxièmement de vérifier si ces modifications peuvent être supprimées par l'administration de doses immunosuppressives de méthylprednisolone (MP). Le dosage des anticorps anti-MBP libres et totaux dans le LCR, après hydrolyse acide, s'est fait grâce à un radio-immunoessai en phase solide (RIA). Lors des poussées de SEP la plus grande partie de l'élévation des anti-MBP est sous forme libre. Les anticorps anti-MBP ne sont pas présents chez les patients SEP en rémission ou chez les témoins non-SEP. Ils sont parfois présents dans la SSEP et chez quelques cas d'encéphalomyélite post-infectieuse. Les taux d'anti-MBP restent élevés sur une période de 10 jours si les patients sont traités par le repos au lit ou à l'aide d'ACTH intraveineux. L'administration intraveineuse (IV) de MP à des doses "élevées" (160 mg/jour) ou "méga" (2g/jour) produisit une réduction fortement significative des MBP $(p<0.001)$. La synthèse intrathécale des IgG totaux est également supprimée par le MP-IV, mais non par l'ACTH. Il semblerait donc que le MP en dose adéquate pourrait remplacer l'ACTH dans le traitement des poussées cliniques de SEP.

Can. J. Neurol. Sci. 1986; 13:25-30

Increased immunoglobulin (IgG) synthesis within the intrathecal compartment (blood brain barrier, BBB) is a hallmark of multiple sclerosis (MS). ${ }^{1-5}$ Cerebrospinal fluid (CSF) IgG or IgG eluted from brain tissue is characterized by oligoclonal banding which is indicative of intrathecal synthesis. ${ }^{6-9}$ MS patients with active or inactive disease have increased intrathecal IgG synthesis of unknown specificity. $5,10,11$

MS patients with exacerbations have elevated CSF myelin basic protein (MBP) levels. ${ }^{5}$ MBP may be an important autoimmunogen in MS since it is chronically and recurrently released into the CSF and the systemic circulation. The recent observation of MBP containing immune complexes in the blood of some MS patients suggests that there is an immune response directed against MBP. ${ }^{12}$ It has also been suggested that high dose prednisone therapy decreases CSF anti-MBP levels. ${ }^{13}$ The purpose of this study was to determine whether autoantibodies to MBP are present in increased titer in CSF of MS patients with exacerbations, and whether intravenous ACTH or methylprednisolone therapies are capable of significantly reducing CSF IgG parameters, MBP and anti-MBP levels. 


\section{MeThoDS}

The $\mathbf{4 0}$ patients entered into this study had clinically definite MS and were experiencing exacerbations. ${ }^{14}$ They were randomly allocated to four treatment groups of 10 patients each: group A - non-treated control group; group B - ACTH 60 units/day intravenously for 10 days; group C - "high" dose methylprednisolone (MP) $160 \mathrm{mg} /$ day intravenously for 10 days and group D - "mega" dose MP 2 g/day intravenously for 10 days. Matched CSF and serum samples were obtained simultaneously from all patients before treatment and within 12 hours of terminating the medication. The untreated control group also had samples obtained 10 days apart.

Total protein (TP), albumin (alb), IgG, MBP as well as free and total anti-MBP levels were measured in CSF. Alb and IgG levels were also determined in serum. The degree of breakdown of the BBB was estimated by the CSF/serum alb ratio. ${ }^{4}$ Intrathecal IgG synthesis was measured by CSF IgG/alb ratio, an IgG Index and daily rate of CNS IgG synthesis. $2,3,4,15,16$ Cerebrospinal fluid MBP, an indicator of disease activity, was determined by radioimmunoassay (RIA). ${ }^{5}$

Free and total CSF anti-MBP levels were determined before and after acid hydrolysis by a solid phase RIA. ${ }^{17} \mathrm{CSF}$ samples were acidified for 1 hour $(\mathrm{pH}=3)$ in order to dissociate possible preformed immune complexes. These samples were neutralized ( $\mathrm{pH}=7$ ) prior to performing the assay. Final IgG concentration was adjusted to $0.010 \mathrm{~g} / \mathrm{l}$ in all CSF samples. Aliquots of $100 \mathrm{uL}$ CSF before and after acid hydrolysis were incubated for 2 hours at room temperature (RT) in immulon plates coated with human-MBP ( 1 ug/well). After 5 washes, goat anti-human Ig was added and incubated for 1 hour at RT. After another 5 washes radiolabelled $\left(I^{125}\right)$ Staph A Protein $(50,000$ counts/well) was added and incubation continued for 2 more hours at RT. Finally, after 5 more washes the wells were counted individually and results were expressed as \% bound total radioactivity (TC). Blanks were performed with each sample to determine nonspecific adherence to uncoated immulon plates. The nonspecific binding ( $\leqslant 1 \% \mathrm{TC}$ ) was subtracted from the respective sample counts. When CSF samples with initially high IgG and anti-MBP values were serially diluted, the antiMBP levels were parallel to the IgG concentrations. This assay was also validated by absorbing CSF anti-MBP with MBP prior to anti-MBP assay. Absorbtion to MBP resulted in complete elimination of anti-MBP from samples that initially had high anti-MBP titers. Two known positive and two negative controls were included with each run. Within assay variability (CV) for 25 sets of duplicates was 3.86 while between assay variability (CV) for one set of quadruplicates over 10 different runs was 7.75 .

Intragroup mean and standard deviations (SD) were calculated for each parameter before and after treatment. The pre and post treatment values were statistically compared by Student's t test.

\section{RESULTS}

"Normal" levels of free and total CSF anti-MBP were determined in a group of 88 control patients consisting of 25 with psychoneurosis, 32 with degenerative disc disease and 31 with various neurological diseases exclusive of MS. CSF free antiMBP was $0.5 \pm 0.3$ while total anti-MBP was $2.3 \pm 0.5$. In this series, the only neurological diseases associated with relatively high titers of CSF anti-MBP in the bound form only were subacute sclerosing panencephalitis and 2 of 8 cases of post infectious encephalomyelitis.

The results of the 4 treatment methods are summarized in Table 1.

Group A - non-treated control group: This group showed no change in any of the measured parameters over the 10 day period. CSF TP and alb as well as the degree of breakdown of the BBB remained approximately the same. Total intrathecal IgG synthesis as measured by three different parameters remained high. CSF-MBP also remained elevated indicating continuation of disease activity. Both free and total CSF anti-MBP levels showed no tendency to drop towards normal values.

Group B - ACTH treatment: With one exception, results of this group were similar to group A. CSF-MBP showed a modest but significant drop from $21.8 \pm 2.2$ to $16.0 \pm 3.2 \mathrm{ug} / \mathrm{L}(\mathrm{p}<0.05)$. The BBB, intrathecal IgG synthesis and CSF anti-MBP showed no significant change.

Group C - "high" dose MP and Group D - "mega" dose MP: CSF TP and alb remained unchanged. The degree of breakdown of the BBB (Figure 1) also remained elevated in these 2 groups. Absolute CSF IgG was significantly lowered from $0.097 \pm 0.013$ to $0.046 \pm 0.002 \mathrm{~g} / \mathrm{L}(\mathrm{p}<0.01)$ by "mega" dose MP; total intrathecal IgG synthesis was also more significantly suppressed by "mega" dose treatment: CSF IgG/alb ratio was significantly lowered from $0.58 \pm 0.06$ to $0.23 \pm 0.07(p<0.01)$ by

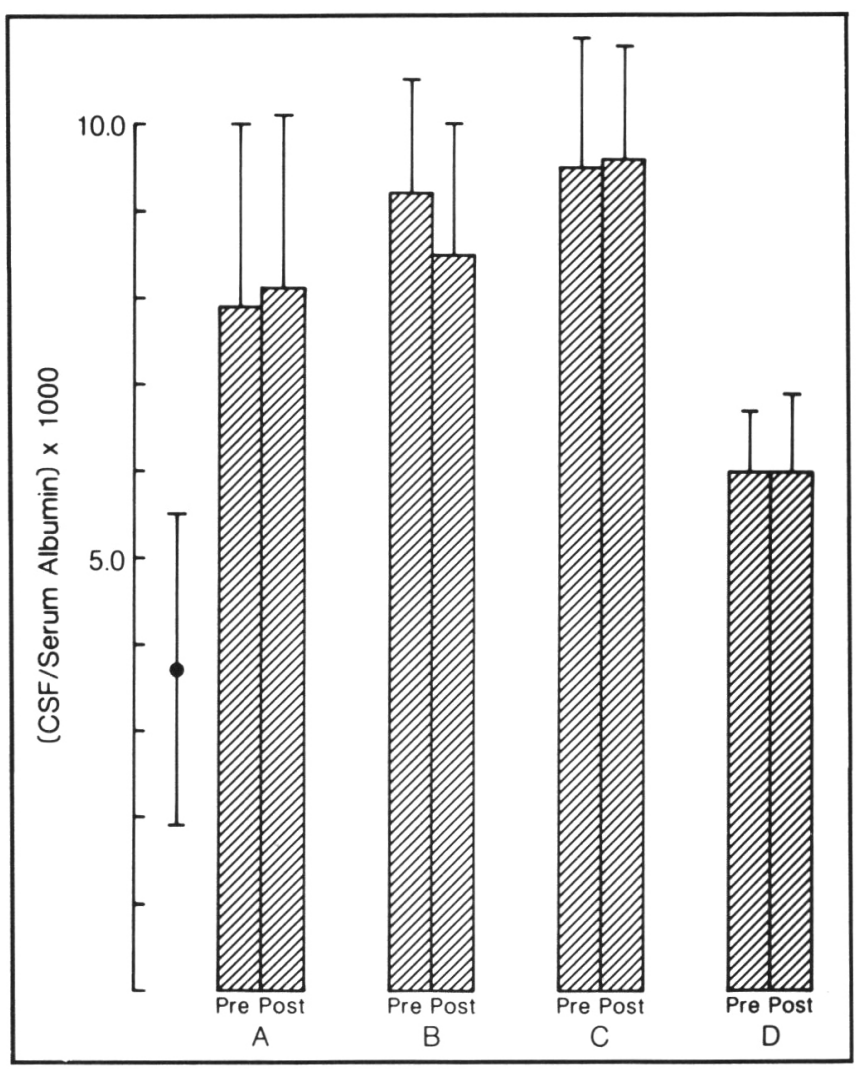

Figure $1-$ Pre and post treatment blood brain barrier values (mean $\pm 2 S D$ ) as measured by (CSF/serum albumin) $\times 1000$ in the four treatment $(A, B, C, D)$ groups. After 10 days of treatment no significant reduction occurred in either the $A C T H(B)$ or methylprednisolone $(C, D)$ groups.

$=$ normal mean $\pm 2 S D$ 
"mega" dose only; IgG Index was reduced from $1.10 \pm 0.18$ to $0.80 \pm 0.16(p<0.01)$ by " high" dose MP and from $2.20 \pm 0.16$ to $1.2 \pm 0.16(\mathrm{p}<0.001)$ by "mega" dose MP (Figure 2).

The greater reduction of the IgG Index by "mega" dose MP was due to higher pretreatment values. However, daily rate of CNS IgG synthesis was also more significantly reduced from $23.8 \pm 2.8$ to $4.4 \pm 2.8$ ( $p<0.001$ ) by "mega" dose, than from $26.4 \pm 5.6$ to $16.0 \pm 2.8 \mathrm{mg} /$ day ( $<<0.01$ ) by "high" dose (Figure 3). Elevated levels of CSF-MBP were equally suppressed from $16.0 \pm 0.8$ to $4.0 \pm 0.6$ ( $p<0.01)$ by "high" dose and from $13.8 \pm 2.9$ to $4.4 \pm 1.6 \mathrm{ug} / \mathrm{L}(\mathrm{p}<0.01)$ by "mega" dose (Figure 4$)$.

CSF free and total anti-MBP levels were elevated in all 40 patients. These parameters were reduced to the same degree by both "high" and "mega" dose MP (Figure 5). Free anti-MBP was suppressed from $24.5 \pm 1.5$ to $6.0 \pm 2.5$ (p<0.001) by "high" dose MP and from $24.0 \pm 2.0$ to $7.5 \pm 2.5$ ( $p<0.001)$ by "mega" dose. Total anti-MBP was reduced from $32.0 \pm 2.0$ to $7.5 \pm 2.5$ ( $p<0.001$ ) by "high" dosage and from $26.4 \pm 3.6$ to $8.5 \pm 2.5$ by "mega" dosage.

\section{Discussion}

Although intrathecal IgG synthesis is significantly increased in MS patients with exacerbations, it was not the purpose of this study to determine how much of the total CSF IgG was

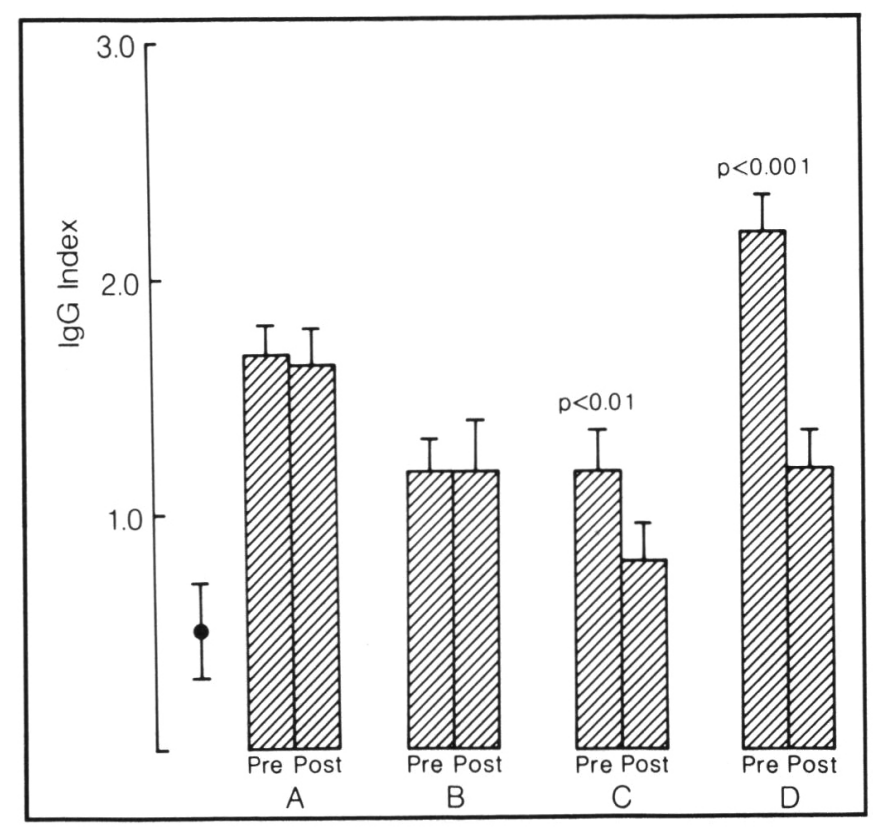

Figure 2 - Intrathecal IgG synthesis as indicated by the $\lg G$ Index (mean $\pm 2 S D$ ) is illustrated for the four treatment groups. A significant reduction occurred in both methylprednisolone groups (C and D).

$=$ normal mean $\pm 2 S D$

Table 1: Effects ACTH and Methylprednisolone on CSF parameters (mean \pm 2 SD) of MS patients with exacerbations Normal values (mean $\pm 2 \mathrm{SD}$ ) are listed below each parameter in the left column.

\begin{tabular}{|c|c|c|c|c|c|c|c|c|}
\hline & Pre & Post & Pre & Post & Pre & Post & Pre & Post \\
\hline $\begin{array}{c}\text { CSF Total Protein } \\
0.35 \pm 0.10\end{array}$ & $0.64 \pm 0.30$ & $0.60 \pm 0.25$ & $0.54 \pm 0.20$ & $0.46 \pm 0.14$ & $0.76 \pm 0.25$ & $0.69 \pm 0.21$ & $0.46 \pm 0.04$ & $0.39 \pm 0.05$ \\
\hline $\begin{array}{l}\text { CSF Albumin } \\
0.164 \pm 0.048\end{array}$ & $0.294 \pm 0.086$ & $0.294 \pm 0.086$ & $0.288 \pm 0.048$ & $0.280 \pm 0.052$ & $0.380 \pm 0.060$ & $0.326 \pm 0.048$ & $0.380 \pm 0.060$ & $0.332 \pm 0.048$ \\
\hline $\begin{array}{l}\text { CSF IgG } \\
\quad 0.024 \pm 0.016\end{array}$ & $0.106 \pm 0.02$ & $0.120 \pm 0.02$ & $0.086 \pm 0.006$ & $0.069 \pm 0.013$ & $0.106 \pm 0.024$ & $0.086 \pm 0.006$ & $0.097 \pm 0.130$ & $0.046 \div 0.002$ \\
\hline $\begin{array}{c}\text { CSF IgG/Albumin } \\
0.14 \pm 0.06\end{array}$ & $0.42 \pm 0.05$ & $0.44 \pm 0.11$ & $0.31 \pm 0.10$ & $0.29 \pm 0.08$ & $0.25 \pm 0.07$ & $0.21 \pm 0.04$ & $0.58 \pm 0.06$ & $0.23 \pm 0.07$ \\
\hline $\begin{array}{l}\text { IgG Index } \\
0.5 \pm 0.1\end{array}$ & $1.68 \pm 0.12$ & $1.64 \pm 0.16$ & $1.10 \pm 0.14$ & $1.10 \pm 0.22$ & $1.10 \pm 0.18$ & $0.80 \pm 0.16$ & $2.20 \pm 0.16$ & $1.20 \pm 0.16$ \\
\hline $\begin{array}{c}\text { Free Anti-MBP } \\
0.4 \pm 0.2\end{array}$ & $20.0 \pm 2.0$ & $20.5 \pm 2.0$ & $19.0 \pm 2.5$ & $20.5 \pm 4.0$ & $24.5 \pm 1.5$ & $6.0 \pm 2.5$ & $24.0 \pm 2.0$ & $7.5 \pm 2.5$ \\
\hline Total Anti-MBP & $22.5 \pm 2.5$ & $23.6 \pm 3.5$ & $22.5 \pm 2.5$ & $22.5 \pm 4.0$ & $32.0 \pm 2.0$ & $7.5 \pm 2.5$ & $26.4 \pm 3.6$ & $8.5 \pm 2.5$ \\
\hline
\end{tabular}

Pre $=$ data prior to treatment $($ day 0$) \quad$ Post $=$ data after 10 days of treatment.

Student's t test $\mathrm{p}$ value: $\quad . .=p<0.05$

$\ddot{* . *}=p<0.01$

$\cdots=p<0.001$

Group A (non-treated): No significant change occurred in any parameter.

Group B (ACTH 60 u/day): A modest but significant $\left(^{*}\right)$ drop occurred in CSF MBP levels only.

Group C (Methylprednisolone $160 \mathrm{mg} /$ day): Significant reductions occurred in $\operatorname{lgG} \operatorname{lndex}\left({ }^{* *}\right)$, daily CNS $\operatorname{lgG}$ synthesis $\left({ }^{* *}\right)$, CSF-MBP $\left({ }^{* *}\right)$ and both free and total anti-MBP $(* * *)$.

Group D (Methylprednisolone 2 g/day): Significant reductions occurred in CSF IgG $\left({ }^{* *}\right)$, CSF IgG/albumin ratio $\left({ }^{* *}\right)$, IgG Index and daily IgG synthesis $\left({ }^{* *}\right)$, CSF-MBP $(* *)$ and free and total anti-MBP levels $\left({ }^{* * *}\right)$. 


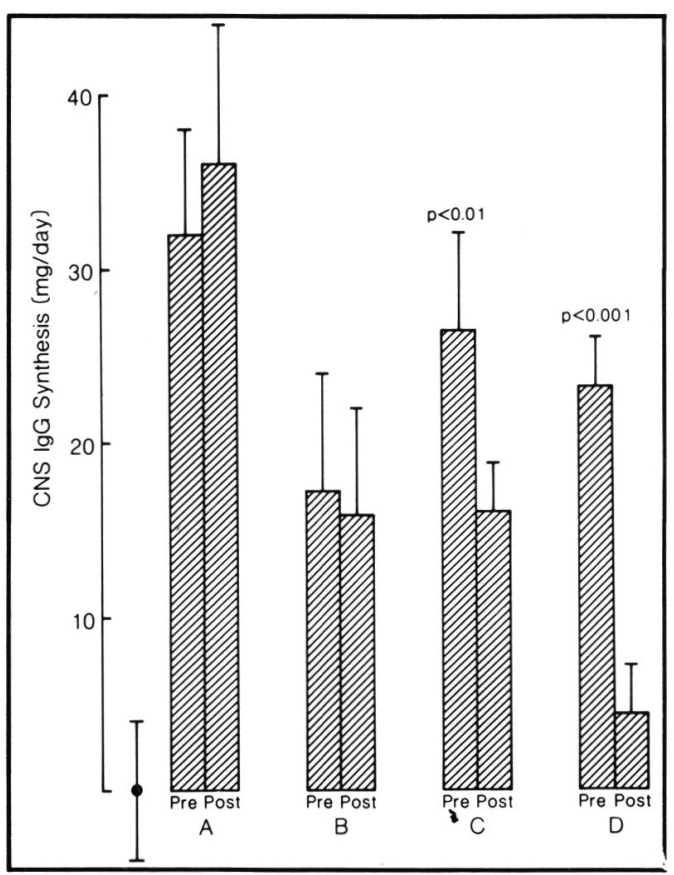

Figure 3 - Intrathecal lgG synthesis as indicated by daily CNS IgG synthesis (mean $\pm 2 S D$ ) is illustrated for the four treatment groups. A significant reduction occurred in both methylprednisolone groups $(C$ and $D)$.

$=$ normal mean $\pm 2 S D$

antibody with specificity for MBP. Nevertheless, CSF antiMBP antibodies were detected in these patients by a solid phase RIA using human MBP (whole molecule). ${ }^{17}$ Recently, Panitch et al, ${ }^{18}$ using a RIA with guinea pig MBP, reported low anti-MBP levels in MS patients with exacerbations. While other authors have found antibodies against MBP in MS CSF, ${ }^{19,20}$ there have also been reported negative results. ${ }^{21}$ In the present report, high CSF anti-MBP levels were found in MS patients with clinical exacerbations associated with elevated CSF-MBP levels. With the exception of a patient with SSPE and 2 of 8 patients with post infectious encephalomyelitis, a large control group of psychiatric and other neurological diseases had no detectable anti-MBP in the CSF. The fact that anti-MBP was somewhat higher after acid hydrolysis may be explained by the presence of immune complexes in CSF. The data illustrate high free to total anti-MBP ratios, therefore an exacerbation of MS may be dependent upon a pulse of anti-MBP molecules being produced intrathecally.

When MS exacerbations were managed for 10 days by bed rest only, all CSF parameters remained unchanged and abnormally elevated. The BBB remained impaired permitting leakage of serum proteins into the intrathecal compartment. CNS IgG synthesis continued at the same rate, and disease activity as indicated by elevated CSF-MBP was maintained. Anti-MBP antibodies persisted at high levels.

It has previously been suggested that short term, high dosage use of intramuscular ACTH hastened improvement of symptoms and signs of MS patients with exacerbations and that de novo CNS IgG synthesis was reduced by ACTH therapy. 22,23 In the present report, the IV administration of 60 units ACTH/day for 10 days had a negligible effect on all CSF parameters. As noted in the untreated group, the BBB remained impaired and

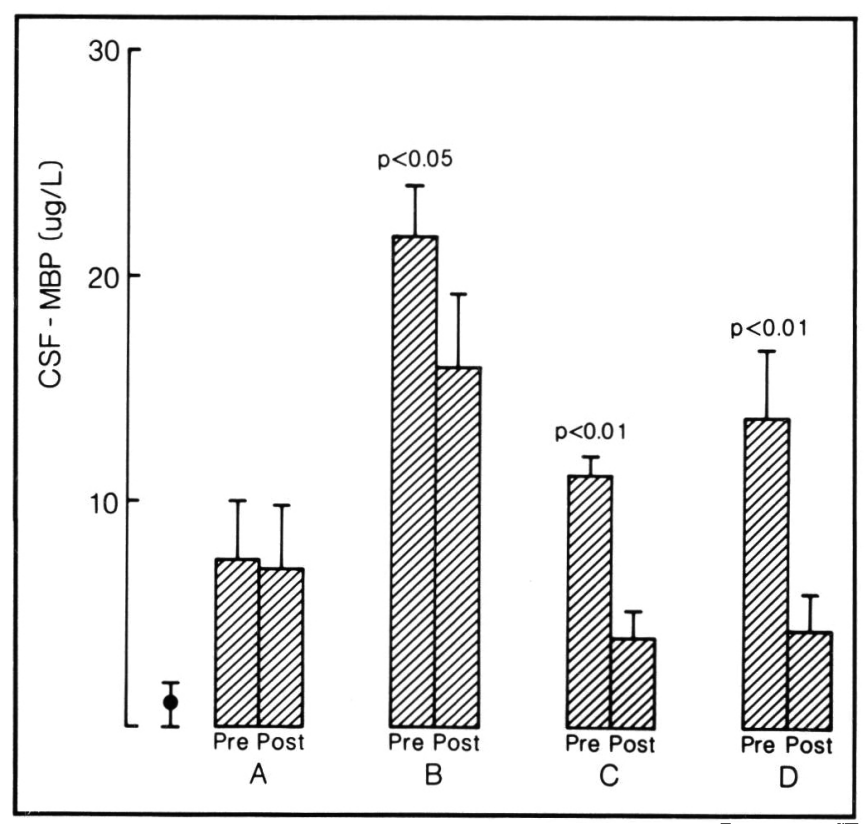

Figure 4-Disease activity as indicated by CSF-MBP (mean $\pm 2 S D)$ levels is illustrated for the four treatment groups. A modest but significant reduction was produced by $A C T H(B)$ and a more significant reduction was produced by methylprednisolone therapies $(C$ and $D)$.

$$
=\text { normal mean } \pm 2 S D
$$

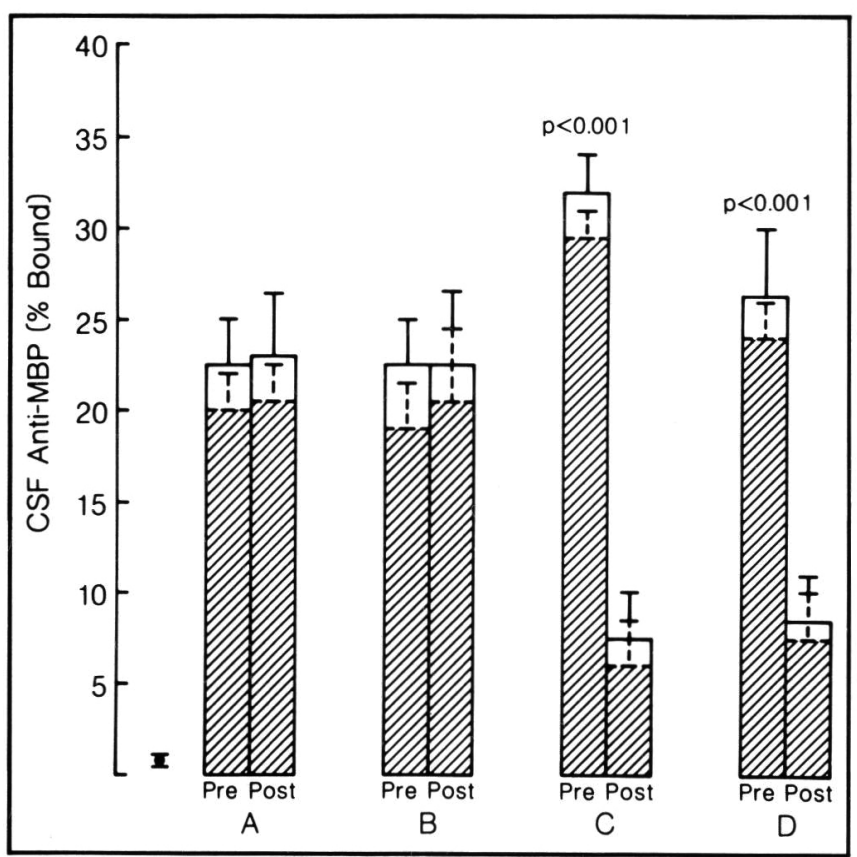

Figure $5-$ Free and total CSF anti-MBP levels (mean $\pm 2 S D$ ) are illustrated for the four treatment groups.

Hatched area $=$ free anti-MBP (prior to acid hydrolysis). Total area $=$ total anti-MBP (post acid hydrolysis).

Group A - no change.

Group $B-$ no change.

Group $C$ and $D-a$ highly significant reduction in both free and total anti-MBP after 10 days of $I V$ methylprednisolone therapy. 
intrathecal IgG synthesis was maintained. While CSF antiMBP levels persisted there was a modest reduction of CSF-MBP.

Uncontrolled clinical observations have suggested that IV-MP may be of clinical value for MS patients with active disease. ${ }^{23-27}$ A dose of $\lg$ MP per day administered to MS patients with exacerbations reduced contrast enhancing lesions detected by computed tomography. ${ }^{28}$ In the present study the BBB as measured by the $\mathrm{CSF} /$ serum alb ratio remained unchanged. It has also been suggested that a large dose of $1 \mathrm{~g}$ MP per day may result in suppression of CNS IgG synthesis. ${ }^{29}$ In this report two dosage regimes of MP were studied: a "high" dose ( $160 \mathrm{mg} /$ day $)$ as well as a "mega" dose ( $2 \mathrm{~g} /$ day). In contrast to the untreated or ACTH treated groups the MP therapies produced marked changes in many of the CSF parameters. Although the "mega" dosage produced a more significant drop, intrathecal IgG synthesis was significantly reduced by both MP regimes. Both MP therapies similarly reduced disease activity as measured by CSF-MBP. Free and total CSF anti-MBP levels were also significantly reduced by MP in either dosage. The effects of the "high" dose administration was nearly equivalent to that produced by "mega" dose. Adverse clinical side effects including acute psychosis and attempted suicide, hair loss, steroid withdrawal skin rashes, cataract formation and aseptic necrosis of the femoral head were unacceptably high in the group of patients who received "mega" dose therapy in this study. These side effects did not occur in patients who received the lower dosage $(160 \mathrm{mg} /$ day $)$. According to the results observed in this study, it may not therefore be necessary to give "mega" dosages of MP to MS patients. However, biological effects not measured in this study may only occur with "mega" dosage therapy.

In conclusion, the results of this study suggest that IV-MP is of greater value than ACTH in reducing certain CSF parameters. Unpublished longitudinal case studies of MP treated patients in our Multiple Sclerosis Research Clinic have shown that intrathecal IgG synthesis, CSF MBP and anti-MBP levels remained suppressed and the disease remained clinically inactive for periods up to 6 to 12 months. Conversely, other cases with more aggressive disease, responded negligibly to MP therapy.

Since some of the intrathecally produced IgG may be protective, suppression of total IgG by MP may be detrimental. However, suppression of potentially destructive IgG components such as anti-MBP would convert an active disease process into an inactive one and the protective antibodies may no longer be required. Because CSF anti-MBP levels are increased in MS patients with active disease but not in patients in remission anti-MBP may be involved in the pathogenesis of demyelination. Doubleblind controlled clinical trials of MP therapy with monitoring of the role of anti-MBP are required.

\section{ACKNOWLEDGEMENTS}

We would like to thank the MS patients of Northern Alberta who participated in this project. Assistance with patient care was provided by Ms. P. Shaw, Ms. D. Olmstead and Ms. J. Christopherson. Ms. Christopherson was supported by the MS Society of Canada (Alberta Division). Financial support for this research was provided by MS benefactors including Mr. and Mrs. Philip May and the Friends of MS Patient Care and Research Clinic, Mr. Clifford Giese, Mrs. E. Laforge and the Tegler Foundation (Edmonton) and Mrs. G. Gerth and friends, Barrhead, Canada.

\section{REFERENCES}

1. Kabat EA, Glusman M, Knaub V. Quantitative estimation of the albumin and gamma globulin in normal and pathologic cerebrospinal fluid by immunochemical methods. Am J Med 1948; 4: 653-662.

2. Link $H$, Tibbling $G$. Principles of albumin and IgG analyses in neurological disorders. II. Evaluation of $\operatorname{lgG}$ synthesis within the central nervous system in multiple sclerosis. Scand J Clin Lab Invest 1977; 37: 397-401.

3. Tourtellotte WW. On cerebrospinal fluid IgG quotients in multiple sclerosis and other diseases. A review and a new formula to estimate the amount of IgG synthesized per day by the central nervous system. J Neurol Sci 1970; 10: 279-304.

4. Tourtellotte WW, Ma B. Multiple schlerosis: The blood brain barrier and the measurement of de novo central nervous system IgG synthesis. Neurol 1978; 28(9): 76-83.

5. Warren KB, Catz I. An investigation of the relationship between cerebrospinal fluid myelin basic protein levels and IgG measurements in multiple sclerosis patients. Ann Neurol 1985; 17: 475-480.

6. Delmotte P. Gel isoelectric focusing of cerebrospinal fluid proteins: A potential diagnostic tool. Z Klin Chem Klin Biochem 1971; 9: 334-336.

7. Johnson KP, Arrigo SC, Nelson BJ, Ginsberg A. Agarose electrophoresis of cerebrospinal fluid in multiple sclerosis. Neurol $1977 ; 27 ; 273-277$.

8. Gilden D, Tachovsky T. Immunoglobulin elution from multiple sclerosis brain. J Neurosci Meth 1979; 1: 133-142.

9. Link H. Oligoclonal IgG in multiple sclerosis brains. J Neurol Sci 1972; 16: 103-114.

10. Mattson DH, Roos RP, Arnason BGW. Isoelectric focusing of IgG eluted from multiple sclerosis and subacute sclerosing panencephalitis brains. Nature 1980; 287: 335-337.

11. Mattson DH, Roos RP, Arnason BGW. Immunoperoxidase staining of cerebrospinal fluid IgG in isoelectric focusing gels: A sensitive new technique. J Neurosci Meth 1980; 3: $67-75$.

12. Dasgupta MK, Catz I, Warren KG et al. Myelin basic protein: A component of circulating immune complexes in multiple sclerosis patients. Can J Neurol Sci 1983; 10(4): 239-243.

13. Wajgt A, Gorny $M$, Jenek $R$. The influence of high dose prednisone medication on autoantibody specific activity and on circulating immune complex level in cerebrospinal fluid of multiple sclerosis patients. Acta Neurol Scand 1983; 68: 378-385.

14. Schumacher GA, Beebe G, Kibler RE et al. Problems of experimental trials of therapy in multiple sclerosis. Ann NY Acad Sci 1965; 122: 552-568.

15. Tourtellotte $W W$. What is multiple sclerosis? Laboratory criteria for diagnosis. In: Hallpike JF, Adams CWM, and Tourtellotte WW, eds. Multiple Sclerosis Research, New York: Elsevier Scientific Publishing Company, 1975: 9-26.

16. Tourtellotte WW, Potvin AR, Fleming I et al. Multiple sclerosis: Measurement and validation of central nervous system IgG synthesis rate. Neurology 1980; 30: 240-244.

17. Warren KG, Catz I. Diagnostic value of CSF anti-MBP in multiple sclerosis patients. Ann Neurol 1986; In press.

18. Panitch HS, Hooper CJ, Johnson KP. CSF antibody to myelin basic protein: Measurement in patients with multiple sclerosis and subacute sclerosing panencephalitis. Arch Neurol 1980; 37: 206-209.

19. Ruutianen J, Arnadottir T, Molner G et al. Myelin basic protein antibodies in the serum and CSF of multiple sclerosis and subacute sclerosing panencephalitis. Acta Neurol Scand 1981;64: 196-206.

20. Wajgt A, Gorny M. CSF antibodies to myelin basic protein and myelin-associated glycoprotein in multiple sclerosis. Evidence of intrathecal production of antibodies. Acta Neurol Scand 1983; 68: $337-343$.

21. Chou CHJ, Tourtellotte WW, Kibler RF. Failure to detect antibodies to myelin basic protein in CSF of patients with MS. Neurology $1983 ; 33$ : $24-28$.

22. Rose AS, Kuzma JN, Kurtzke JF et al. Cooperative study in the evaluation of therapy in multiple sclerosis: ACTH versus placebo. Final report. Neurology 1970; 20 (no. 5-part 2): 1-59.

23. Tourtellotte WW, Baumhefner RW, Potvin AR et al. Multiple sclerosis de novo CNS IgG synthesis: Effect of ACTH and corticosteroids. Neurology 1980; 30: 1155-1162. 
24. Dowling PC, Bosch VV, Cook SD. Possible beneficial effect of high dose intravenous steroid therapy in acute demyelinating disease and transverse myelitis. Neurology 1980; 30(2): 33-36.

25. Brickley C, Kennard C, Swash M. Treatment of acute exacerbations of multiple sclerosis with intravenous methylprednisolone. J Neurol Neurosurg Psychiat 1982; 45: 179-180.

26. Newman PK, Saunders M, Tilley PJB. Methylprednisolone therapy in multiple sclerosis. J Neurol Neurosurg Psychiat 1982; 45: 941-942.

27. Goas M, Marion JL, Missocum A. High dose intravenous methylprednisolone in acute exacerbations of multiple sclerosis. J Neurol Neurosurg Psychiat 1983; 46: 99.
28. Troiano $R$, Hafstein $M$, Nuderman $M$ et al. Effect of high dose intravenous steroid administration on contrast enhancing computed tomographic scan lesions in multiple sclerosis. Ann Neurol 1984; 15: 257-263.

29. Trotter JL, Garvey W. Prolonged suppression of CNS IgG synthesis after large dose "pulse" methylprednisolone therapy in multiple sclerosis. Neurology 1979; 68: 378-385. 